\title{
Sexual dysfunction, mood, anxiety, and personality disorders in female patients with fibromyalgia
}

\author{
This article was published in the following Dove Press journal: \\ Neuropsychiatric Disease and Treatment \\ 16 February 2016 \\ Number of times this article has been viewed
}

\section{Fatih Kayhan' \\ Adem Küçük ${ }^{2}$ \\ Yılmaz Satan ${ }^{3}$ \\ Erdem İlgün ${ }^{4}$ \\ Șevket Arslan ${ }^{5}$ \\ Faik İlik ${ }^{6}$}

'Department of Psychiatry, Faculty of Medicine, Selçuk University,

${ }^{2}$ Department of Rheumatology, Faculty of Medicine, Necmettin Erbakan University, ${ }^{3}$ Department of Psychiatry, Konya Numune State Hospital, ${ }^{4}$ Department of Physical Therapy and Rehabilitation, Faculty of Medicine, Mevlana University, ${ }^{5}$ Department of Internal Medicine, Faculty of Medicine, Necmettin Erbakan University, ${ }^{6}$ Department of Neurology, Faculty of Medicine, Bașkent University, Konya, Turkey
Correspondence: Fatih Kayhan Department of Psychiatry, Faculty of Medicine, Selçuk University, Alaeddin Keykubat Campus, 42। 3 I Selçuklu, Konya, Turkey

Tel +90332 24l 218I

Email drkayhan@yahoo.com
Background: We aimed to investigate the current prevalence of sexual dysfunction (SD), mood, anxiety, and personality disorders in female patients with fibromyalgia (FM).

Methods: This case-control study involved 96 patients with FM and 94 healthy women. The SD diagnosis was based on a psychiatric interview in accordance with the Diagnostic and Statistical Manual of Mental Disorders, fourth edition criteria. Mood and anxiety disorders were diagnosed using the Structured Clinical Interview. Personality disorders were diagnosed according to the Structured Clinical Interview for DSM, Revised Third Edition Personality Disorders.

Results: Fifty of the 96 patients (52.1\%) suffered from SD. The most common SD was lack of sexual desire $(n=36,37.5 \%)$ and arousal disorder $(n=10,10.4 \%)$. Of the 96 patients, $45(46.9 \%)$ had a mood or anxiety disorder and $13(13.5 \%)$ had a personality disorder. The most common mood, anxiety, and personality disorders were major depression (26\%), generalized anxiety disorder (8.3\%), and histrionic personality disorder (10.4\%).

Conclusion: SD, mood, and anxiety disorders are frequently observed in female patients with FM. Pain plays a greater role in the development of SD in female patients with FM.

Keywords: anxiety, depression, fibromyalgia, sexual dysfunction

\section{Introduction}

Sexual dysfunction (SD) is a major public health problem that affects females more than males. ${ }^{1-4}$ Female SD includes lack of sexual desire, sexual aversion, orgasmic disorder, and dyspareunia. ${ }^{5}$ Epidemiological studies indicate that $30 \%-50 \%$ of women complain of SD. ${ }^{2,6}$ Female SD is composed of several medical and psychosocial components ${ }^{7}$ and is also associated with pathological states, including chronic pain. ${ }^{8}$ A high incidence of SD has been reported in patients with fibromyalgia (FM), compared to that in healthy controls. ${ }^{9-13}$ The development of SD in patients with FM is related to several factors, such as pain, fatigue, stiffness, functional disorders, negative body image, sexual abuse, and drug therapy. ${ }^{14}$

FM is a chronic musculoskeletal pain syndrome of unknown etiology characterized by widespread body pain and fatigue. ${ }^{15} \mathrm{FM}$ has been identified by the American College of Rheumatology as a condition of chronic ( $>3$ months) widespread pain perceived on palpitation of at least eleven of 18 tender point sites throughout the body. ${ }^{16}$ Other complaints frequently reported by patients with FM include sleep disorders, anxiety, depression, concentration problems, headache, numbness, and tingling. ${ }^{17} \mathrm{FM}$ has $2 \%$ prevalence in the community and occurs at a four- to sevenfold greater prevalence in women than in men. ${ }^{18,19}$ The prevalence of FM increases with age and is seen more frequently during or around menopause. ${ }^{20}$

Psychiatric disorders are observed frequently in patients with FM. ${ }^{21-26}$ In particular, a significant proportion of patients with FM present with depression. The lifetime 
prevalence of depression in patients with $\mathrm{FM}$ is $50 \%-70 \%$, compared to the spontaneous prevalence rate of $18 \%-36 \% .{ }^{27-29}$ Previous studies have justified including major depressive symptoms in scales for diagnosing depression. ${ }^{27-29}$ However, a limited number of studies have used a semistructured psychiatric interview. Uguz et $\mathrm{al}^{30}$ used the Structured Clinical Interview for the Diagnostic and Statistical Manual of Mental Disorders, fourth edition (DSM-IV) Axis I disorders (SCID-I) and reported that $47.6 \%$ of patients had a psychiatric disorder and $14.6 \%$ presented with major depression.

A few studies have examined the relationship between SD and FM, but they also had significant limitations. SD and comorbid mood and anxiety disorders have been detected in most studies using only scales. Thus, these studies can only provide information about symptoms related to $\mathrm{SD}$ and accompanying depressive symptoms and anxiety, and they do not provide information on the type of SD or the type of psychiatric disorder. Furthermore, the studies that have used a structured psychiatric interview were carried out with a limited number of patients. The personality disorders in patients with FM that may lead to SD and an Axis I psychiatric disorder have not been assessed previously together.

In this study, we investigated the relationships between SD and mood, anxiety, and personality disorders, as well as their effects on quality of life in patients with FM. This is the first study to evaluate this combination of factors in patients with FM.

\section{Methods}

This study included 125 female patients diagnosed with FM according to the American College of Rheumatology criteria who were admitted to the outpatient Physical Therapy Unit of Mevlana University School of Medicine. Patients who met the inclusion criteria were enrolled in the study after providing written and verbal consent.

The inclusion criteria were 1 ) $\geq 18$ years of age; 2 ) married; and 3) no use of psychotropic drugs, such as antidepressant, anxiolytic, or antipsychotic drugs, in the previous 3 months for any reason.

The exclusion criteria were 1) $<18$ years of age; 2 ) menopausal; 3) history of urologic surgery; 4) use of medication for a chronic medical illness; 5) mental retardation; 6) history and current diagnosis of a psychiatric disorder; and 7) use of psychotropic drugs, such as antidepressant or anxiolytic drugs, in the past 3 months for any reason.

Of the 125 enrolled patients with FM, 15 were excluded due to the continued use of psychotropic drugs, five patients due to chronic medical condition, and two patients because of a history of pelvic surgery; seven patients did not want to participate in the study. The final study group consisted of 96 patients with FM. The control group consisted of 94 female volunteers from the general population who met the inclusion and exclusion criteria and had not been diagnosed with FM or chronic pain but matched the patient cohort in sociodemographic characteristics.

This study was approved by the Ethics Committee of Mevlana University. The characteristics and procedures of the study were explained to the study participants, and oral and written informed consent was obtained from all of the participants. The sociodemographic and FM characteristics of the patients were recorded using a semistructured questionnaire developed by the authors. FM diagnoses were made based on the American College of Rheumatology criteria. ${ }^{16}$ The visual analog scale (VAS) was used to determine the pain intensity. ${ }^{31}$ Once the sociodemographic characteristics of the patients were recorded, they were referred to the Psychiatric Outpatient Clinic where psychiatric disorders and SD diagnoses were made after a psychiatric interview. Psychiatrists, who were blinded to the rheumatological conditions of the patients, evaluated the patients for mood and anxiety disorders using the clinical version of the SCID-I. ${ }^{32}$ Personality disorders were diagnosed with the Structured Clinical Interview for DSM, Revised Third Edition Personality Disorders. ${ }^{33}$ The SD diagnosis was made through a psychiatric interview and was based on the criteria stated in the DSM-IV. The Hamilton Depression Rating Scale ${ }^{34}$ and the Hamilton Anxiety Rating Scale ${ }^{35}$ were used to determine levels of depression and anxiety, respectively.

SPSS Version 16.0 for Windows software (SPSS Inc., Chicago, IL, USA) was used for the data analysis. Normality of the data distributions was checked with the KolmogorovSmirnov test. The chi-square or Fisher's exact test was applied to compare categorical variables. The $t$-test or the Mann-Whitney $U$-test was used to analyze numerical variables. A multivariate binary logistic regression analysis was conducted to determine independent factors associated with SD. A two-tailed $P$-value $<0.05$ was considered significant.

\section{Results}

The mean age of the participants ( $\mathrm{n}=190)$ was $37.75 \pm 6.24$ years. The majority of women were unemployed $(n=172,90.5 \%)$, and the mean number of years of education was $7.45 \pm 3.38$. No differences were detected in sociodemographic characteristics between the patient and the control groups (Table 1). 
Table I Sociodemographic features and HDRS and HARS scores

\begin{tabular}{llll}
\hline & $\begin{array}{l}\text { Patient } \\
\text { group }\end{array}$ & $\begin{array}{l}\text { Control } \\
\text { group }\end{array}$ & P-value \\
\hline $\begin{array}{l}\text { Age (years) mean } \pm \text { StdD } \\
\text { Education (years) mean } \pm \text { StdD }\end{array}$ & $\begin{array}{l}38.27 \pm 6.18 \\
\text { Employment status, } \mathrm{n}(\%)\end{array}$ & $37.23 \pm 6.29$ & $0.214^{\mathrm{a}}$ \\
$\quad \begin{array}{l}\text { Unemployed } \\
\text { HDRS, mean } \pm \text { StdD }\end{array}$ & $84(87.5)$ & $88(93.6)$ & $0.215^{\mathrm{b}}$ \\
HARS, mean \pm StdD & $7.91 \pm 4.10$ & $3.04 \pm 1.83$ & $0.000^{\mathrm{a}}$ \\
\hline
\end{tabular}

Notes: aMann-Whitney U-test. 'Fisher's exact test.

Abbreviations: HDRS, Hamilton Depression Rating Scale; HARS, Hamilton Anxiety Rating Scale; StdD, standard deviation.

Table 2 shows the distribution of SD among the patients with FM and control subjects. According to the DSM-IV criteria, 46 patients (47.9\%) were diagnosed with SD. The most common SDs in patients with FM were lack of sexual desire $(\mathrm{n}=36,37.5 \%)$ and arousal disorder $(\mathrm{n}=10$, $10.4 \%)$. The categories of presence of any SD $(P=0.000)$, sexual desire $(P=0.000)$, orgasm disorder $(P=0.033)$, and arousal disorder $(P=0.049)$ were observed significantly more frequently in the patient group than in the control group. No significant differences in the categories of sexual aversion disorder or dyspareunia were detected between the groups.

Table 2 shows the distribution of psychiatric and personality disorders among the patients with FM and control subjects. Among the patients with FM, 45 (46.9\%) met the minimum criteria for a mood or anxiety disorder based on the SCID-I. Additionally, 27 patients with FM (28.1\%) had a mood disorder, and 18 (18.8\%) had an anxiety disorder. The most common psychiatric disorders were major depression $(n=25,26 \%)$ and generalized anxiety disorder (GAD) $(n=8,8.3 \%)$, and the incidence rates of these disorders were significantly higher in the patient group than those in the controls. No significant differences were observed in the

Table 2 Current prevalence rate of SD, mood, anxiety, and personality disorders in the study groups

\begin{tabular}{|c|c|c|c|c|}
\hline & Patient group, n=96 & Control group, n=94 & Odds ratio $(95 \% \mathrm{CI})$ & $P$-value \\
\hline Any sexual dysfunction & $46(47.9)$ & $12(12.8)$ & $0.15(0.07-0.32)$ & $0.000^{\mathrm{a}}$ \\
\hline Sexual desire disorder & $36(37.5)$ & $13(13.8)$ & $0.26(0.13-0.54)$ & $0.000^{\mathrm{a}}$ \\
\hline Orgasm disorder & $7(7.3)$ & $I(I . I)$ & $0.13(0.01-1.13)$ & $0.033^{a}$ \\
\hline Arousal disorder & $10(10.4)$ & $3(3.2)$ & $0.28(0.07-1.06)$ & $0.049^{a}$ \\
\hline Sexual aversion & $\mathrm{I}(\mathrm{I})$ & 0 & $0.99(0.96-1.10)$ & $1.000^{\mathrm{b}}$ \\
\hline Dyspareunia & $4(4.2)$ & I (I.I) & $0.24(0.02-2.25)$ & $0.368^{b}$ \\
\hline Any mood disorder & $27(28.1)$ & $2(2.1)$ & $0.05(0.01-0.24)$ & $0.000^{\mathrm{a}}$ \\
\hline Major depression & $25(26)$ & $2(2.1)$ & $0.06(0.01-0.26)$ & $0.000^{b}$ \\
\hline Dysthymic disorder & $2(2.1)$ & 0 & $0.97(0.95-1.00)$ & $0.497^{\mathrm{b}}$ \\
\hline Bipolar disorder & 0 & 0 & - & - \\
\hline Any anxiety disorder & $18(18.8)$ & $4(4.3)$ & $0.19(0.06-0.59)$ & $0.002^{a}$ \\
\hline Generalized anxiety disorder & $8(8.3)$ & I (I.I) & $0.11(0.01-0.96)$ & $0.035^{b}$ \\
\hline Panic disorder & $2(2.1)$ & I (I.I) & $0.50(0.04-5.66)$ & $1.000^{\mathrm{b}}$ \\
\hline Social phobia & $2(2.1)$ & I (I.I) & $0.50(0.04-5.66)$ & $1.000^{b}$ \\
\hline Specific phobia & $3(3.1)$ & $2(2.1)$ & $0.67(0.11-4.12)$ & $1.000^{\mathrm{b}}$ \\
\hline Posttraumatic stress disorder & 0 & 0 & - & - \\
\hline Not otherwise specified anxiety disorder & $6(6.2)$ & I (I.I) & $0.16(0.04-1.36)$ & $0.118^{b}$ \\
\hline Obsessive-compulsive disorder & $2(2.1)$ & I (I.I) & $0.50(0.04-5.66)$ & $1.000^{\mathrm{b}}$ \\
\hline Any mood or anxiety disorder & 45 (46.9) & $5(5.3)$ & $0.06(0.02-0.17)$ & $0.000^{\mathrm{b}}$ \\
\hline Any axis II disorder & $13(13.5)$ & $5(5.3)$ & $0.35(0.12-1.05)$ & $0.053^{\mathrm{a}}$ \\
\hline Avoidant & $2(2.1)$ & 0 & $0.97(0.95-1.00)$ & $0.497^{b}$ \\
\hline Dependent & $2(2.1)$ & I (I.I) & $0.50(0.04-5.66)$ & $1.000^{\mathrm{b}}$ \\
\hline Obsessive compulsive & I (I) & $2(2.1)$ & $2.06(0.18-23.16)$ & $0.619^{b}$ \\
\hline Passive-aggressive & $2(2.1)$ & 0 & $0.97(0.95-1.00)$ & $0.497^{b}$ \\
\hline Paranoid & 0 & 0 & - & - \\
\hline Schizotypal & 0 & 0 & - & - \\
\hline Schizoid & 0 & 0 & - & - \\
\hline Histrionic & $10(10.4)$ & I (I.I) & $0.09(0.01-0.73)$ & $0.006^{a}$ \\
\hline Borderline & 0 & 0 & - & - \\
\hline Narcissistic & 0 & 0 & - & - \\
\hline Antisocial & 0 & 0 & - & - \\
\hline Comorbidity of any psychiatric and personality disorder & $10(10.4)$ & $2(2.1)$ & $0.18(0.04-0.87)$ & $0.019^{a}$ \\
\hline
\end{tabular}

Notes: ${ }^{a} \chi^{2}$ test. ${ }^{b}$ Fisher's exact test. Values shown in bold are statistically significant.

Abbreviations: $\mathrm{SD}$, sexual dysfunction; $\mathrm{Cl}$, confidence interval. 
frequencies of dysthymic disorder, panic disorder, obsessivecompulsive disorder (OCD), a specific phobia, or social anxiety disorder between the patient and the control groups. None of the participants had posttraumatic stress disorder or a bipolar disorder (Table 2).

Among the patients with FM, $13(13.5 \%)$ had a personality disorder. Specifically, histrionic personality disorder was the most common personality disorder among patients with FM $(n=10,10.4 \%)$ and was significantly more prevalent in the patient group than in the control group $(P=0.006)$. No significant difference in the incidence of any personality disorder was observed between the two groups. Similarly, no differences in paranoid, schizoid, schizotypal, borderline, narcissistic, or antisocial personality disorder were observed between the groups (Table 2). The incidence of coexistence of any psychiatric and any personality disorder was $10.4 \%$ (10) in patients with FM, and it is higher than the control group $(P=0.019)$.

$\mathrm{SD}$ was more frequently seen in patients with a low education level when sociodemographic data were compared in patients with FM, with and without SD ( $P=0.012$; Table 3$)$. The relationships between psychiatric disorders and SD in patients with FM are shown in Table 4. Patients with FM and SD had a significantly higher incidence of a psychiatric disorder $(P=0.001)$ and an anxiety disorder $(P=0.022)$. Specifically, the most common psychiatric disorders were major depression $(n=14,30.4 \%)$, not otherwise specified anxiety disorders $(n=6,13 \%)$, and $\operatorname{GAD}(n=4,8.7 \%)$. Patients with FM and reduced sexual desire were significantly more frequently diagnosed with a psychiatric disorder $(P=0.001)$, an anxiety disorder $(P=0.022)$, a not otherwise specified anxiety disorder $(P=0.002)$, or a specific phobia $(P=0.023)$. Patients with FM and sexual aversion disorder also had a significantly higher incidence of OCD $(P=0.021)$, whereas patients with

Table 3 Sociodemographic features and HDRS, HARS, and VAS scores in patients with/without SD

\begin{tabular}{llll}
\hline & $\begin{array}{l}\text { Patients with } \\
\text { SD (mean } \pm \text { StdD) }\end{array}$ & $\begin{array}{l}\text { Patients without } \\
\text { SD (mean } \pm \text { StdD) }\end{array}$ & P-value $^{\text {a }}$ \\
\hline $\begin{array}{l}\text { Age (years) } \\
\begin{array}{l}\text { Education } \\
\text { (years) }\end{array}\end{array}$ & $36.92 \pm 7$ & $39.73 \pm 4.80$ & 0.060 \\
$\begin{array}{l}\text { Duration of } \\
\text { FM (months) }\end{array}$ & $52.34 \pm 2.94$ & $7.72 \pm 3.35$ & $\mathbf{0 . 0 1 2}$ \\
HDRS & $8.45 \pm 4.09$ & $49.44 \pm 37.41$ & 0.953 \\
HARS & $12.43 \pm 6.45$ & $7.42 \pm 4.08$ & 0.204 \\
VAS & $7.21 \pm 1.26$ & $9.36 \pm 6.35$ & $\mathbf{0 . 0 0 7}$ \\
\hline
\end{tabular}

Notes: aMann-Whitney U-test. Values shown in bold are statistically significant. Abbreviations: VAS, visual analog scale; SD, sexual dysfunction; FM, fibromyalgia; HDRS, Hamilton Depression Rating Scale; HARS, Hamilton Anxiety Rating Scale; StdD, standard deviation.
FM and dyspareunia had a significantly higher incidence of $\operatorname{GAD}(P=0.034)$.

No significant relationship was found between patients with FM and SD and a personality disorder $(P=0.891)$. Specifically, patients with FM and sexual aversion disorder were significantly more frequently diagnosed with avoidant personality disorder $(P=0.021)$ and dependent personality disorder $(P=0.021)$.

A multivariate logistics regression analysis revealed that VAS (Wald $x^{2}=4.95$, standard error [SE], 0.27; odds ratio [OR], 1.816; $P=0.026)$ was an independent variable for SD. Any psychiatric disorder (Wald $x^{2}=0.218$; SE, 0.83; OR, 1.477; $P=0.641$ ), any anxiety disorder (Wald $x^{2}=3.38$; SE, 1.41; OR, 0.074; $P=0.066$ ), education (Wald $x^{2}=1.04$; SE, 0.99; OR, 0.904; $P=0.308$ ), age (Wald $x^{2}=3: 55$; SE, 0.53; OR, 1.104; $P=0.059)$, and Hamilton Anxiety Rating Scale (Wald $x^{2}=0.33$; SE, 0.88; OR, 0.984; $P=0.855$ ) were not independent factors.

\section{Discussion}

This is the first study to evaluate SD and mood, anxiety, and personality disorders in female patients with FM. The prevalence of any SD disorder was $47.9 \%$ in our study, and this value was significantly higher in the patient cohort than that in the control group (12.8\%). Many studies have investigated the association between SD and FM. ${ }^{9-12,17,36-40}$ da Costa et $\mathrm{al}^{36}$ reported that patients with FM resort to significant modifications in their sexual activities and experience difficulties with orgasm. Shaver et $\mathrm{al}^{9}$ conducted telephone interviews to study SD in 442 patients with FM and 205 controls and reported that sexual arousal and orgasm decreased in patients with FM and that the patients experienced pain during intercourse. Female Sexual Function Index scores are lower in patients with FM than those in the control group. ${ }^{11,12,40}$ The important feature of our study was that none of the patients with FM included in the study were treated with psychotropic regimen. As might be expected, most of the psychotropic drugs may lead to SD as a side effect. However, there were no clear clinical data regarding the use of psychotropic drugs in such patients in previous studies.

We found that patients with FM who had impaired sexual function also had a lower educational level. Similarly, Prins et $\mathrm{al}^{38}$ reported that patients with FM and SD had a lower educational level those in the control group. However, several studies have reported no effect of educational level on SD. ${ }^{10,40}$ In our study, we found a significant relationship between SD and pain intensity on the VAS in patients with FM. VAS scores in patients with FM and SD were higher than those 
Table 4 The distribution of mood and anxiety disorders according to sexual dysfunction

\begin{tabular}{|c|c|c|c|c|c|c|}
\hline Psychiatric disorders & $\begin{array}{l}\text { Any sexual } \\
\text { dysfunction; n (\%), } \\
\text { P-value }\end{array}$ & $\begin{array}{l}\text { Sexual } \\
\text { desire; n (\%), } \\
P \text {-value }\end{array}$ & $\begin{array}{l}\text { Orgasm } \\
\text { disorder; n (\%), } \\
\text { P-value }\end{array}$ & $\begin{array}{l}\text { Arousal } \\
\text { disorder; n (\%), } \\
\text { P-value }\end{array}$ & $\begin{array}{l}\text { Sexual } \\
\text { aversion; n (\%), } \\
\text { P-value }\end{array}$ & $\begin{array}{l}\text { Dyspareunia; } \\
\text { n (\%), P-value }\end{array}$ \\
\hline \multirow[t]{2}{*}{ Any mood disorder } & $16(34.8)$ & $14(38.9)$ & 0 & $2(20)$ & 0 & 0 \\
\hline & $0.164^{\mathrm{a}}$ & $0.100^{\mathrm{a}}$ & 0.086 & $0.546^{\mathrm{a}}$ & $1.000^{\mathrm{b}}$ & $1.000^{\mathrm{b}}$ \\
\hline \multirow[t]{2}{*}{ MD } & $14(30.4)$ & $13(36.1)$ & 0 & $\mathrm{I}(\mathrm{I0})$ & 0 & 0 \\
\hline & $0.082^{\mathrm{a}}$ & $0.082^{\mathrm{a}}$ & $0.103^{a}$ & $0.222^{\mathrm{a}}$ & $1.000^{\mathrm{b}}$ & $0.570^{\mathrm{a}}$ \\
\hline \multirow[t]{2}{*}{ DD } & $2(4.3)$ & $\mathrm{I}(2.8)$ & 0 & $\mathrm{I}(\mathrm{I0})$ & 0 & 0 \\
\hline & $0.227^{b}$ & $1.000^{\mathrm{b}}$ & $0.689^{a}$ & $0.198^{b}$ & $1.000^{\mathrm{b}}$ & $1.000^{\mathrm{a}}$ \\
\hline \multirow[t]{2}{*}{ BPD } & 0 & 0 & 0 & 0 & 0 & 0 \\
\hline & - & - & - & - & - & - \\
\hline \multirow[t]{2}{*}{ Any anxiety disorder } & $13(28.3)$ & II (30.6) & I (I4.3) & $4(40)$ & $\mathrm{I}(100)$ & $2(50)$ \\
\hline & $0.022^{a}$ & $0.022^{\mathrm{a}}$ & 0.753 & $0.069^{a}$ & $0.187^{b}$ & $0.158^{b}$ \\
\hline \multirow[t]{2}{*}{ GAD } & $4(8.7)$ & $2(5.6)$ & 0 & $2(20)$ & 0 & $2(50)$ \\
\hline & $1.000^{\mathrm{b}}$ & $0.446^{\mathrm{a}}$ & $0.407^{a}$ & $0.158^{a}$ & $1.000^{\mathrm{b}}$ & $0.034^{b}$ \\
\hline \multirow[t]{2}{*}{ PD } & $2(4.3)$ & $2(5.6)$ & 0 & 0 & 0 & 0 \\
\hline & $0.227^{b}$ & $0.138^{b}$ & $0.689^{a}$ & $1.000^{\mathrm{b}}$ & $1.000^{\mathrm{b}}$ & $1.000^{\mathrm{b}}$ \\
\hline \multirow[t]{2}{*}{ SAD } & $2(4.3)$ & $2(5.6)$ & I & $I(10)$ & 0 & 0 \\
\hline & $0.227^{b}$ & $0.138^{b}$ & $0.14 I^{b}$ & $0.198^{b}$ & $1.000^{\mathrm{b}}$ & $1.000^{\mathrm{b}}$ \\
\hline \multirow[t]{2}{*}{ SP } & $3(6.5)$ & 3 & 0 & 0 & 0 & 0 \\
\hline & $0.106^{b}$ & $0.023^{b}$ & $1.000^{\mathrm{b}}$ & $1.000^{\mathrm{b}}$ & $1.000^{\mathrm{b}}$ & $1.000^{\mathrm{b}}$ \\
\hline \multirow[t]{2}{*}{ PTSD } & 0 & 0 & 0 & 0 & 0 & 0 \\
\hline & - & - & - & - & - & - \\
\hline \multirow[t]{2}{*}{ OCD } & I (2.2) & I (2.8) & 0 & 0 & $I(100)$ & 0 \\
\hline & $1.000^{\mathrm{b}}$ & $1.000^{\mathrm{b}}$ & $1.000^{\mathrm{b}}$ & $1.000^{\mathrm{b}}$ & $0.02 I^{b}$ & $1.000^{\mathrm{b}}$ \\
\hline \multirow[t]{2}{*}{ NOS anxiety disorder } & $6(13)$ & 6 & $2(28.6)$ & $2(20)$ & 0 & 0 \\
\hline & $0.010^{\mathrm{b}}$ & $0.002^{b}$ & $0.0 \mathrm{II}^{\mathrm{a}}$ & $0.058^{a}$ & $1.000^{\mathrm{b}}$ & $1.000^{\mathrm{b}}$ \\
\hline \multirow[t]{2}{*}{ Any psychiatric disorder } & $29(63)$ & $25(69.4)$ & $2(28.6)$ & $6(60)$ & 0 & $2(50)$ \\
\hline & $0.00 I^{a}$ & $0.00 \mathrm{I}^{\mathrm{a}}$ & $0.442^{\mathrm{b}}$ & $0.380^{\mathrm{a}}$ & $1.000^{\mathrm{b}}$ & $1.000^{\mathrm{b}}$ \\
\hline Comorbidity of any psychiatric & $6(13)$ & $4(I I . I)$ & 0 & $2(20)$ & 0 & 0 \\
\hline and any personality disorder & $0.419^{a}$ & $0.863^{\mathrm{a}}$ & - & $0.295^{\mathrm{a}}$ & - & - \\
\hline
\end{tabular}

Notes: a $\chi^{2}$ test. ${ }^{b}$ Fisher's exact test. Values shown in bold are statistically significant.

Abbreviations: MD, major depression; DD, dysthymic disorder; BPD, bipolar disorder; GAD, generalized anxiety disorder; PD, panic disorder; SAD, social anxiety disorder; SP, specific phobia; PTSD, posttraumatic stress disorder; OCD, obsessive-compulsive disorder; NOS, not otherwise specified.

in patients with FM without SD. Pain plays a role in the development of SD in patients with rheumatoid arthritis and ankylosing spondylitis. ${ }^{8}$ However, a moderate correlation has been suggested between SD and pain in most but not all patients with $\mathrm{FM},{ }^{9}$ whereas sexual function and satisfaction reportedly play a minor role. ${ }^{39}$

One of the most important findings from our study is that SD was significantly more frequent in patients with FM and any mood or anxiety disorder and that $63 \%(n=29)$ of patients with FM and SD had a mood or anxiety disorder. The presence of a mood and anxiety disorder was also significantly higher in patients with FM without SD, as compared to the control group. No similar study has compared the variables that we compared in our study. It has been reported that patients with FM and SD have higher depression scores. ${ }^{11,39,40}$ Community-based studies indicate that women with SD very frequently also have a psychiatric disorder.

Another objective of our study was to understand the effects of depression on SD. Tikiz et al ${ }^{12}$ reported no significant difference in the prevalence of SD in patients with FM with and without depression. These findings are consistent with the findings of our study. Studies reporting an association between SD and depression scores are available. ${ }^{11,39,40}$ Depression also plays a role as an independent SD variable in patients with FM. ${ }^{39}$ Studies that have reported an association between depression and SD used scales to evaluate depressive symptoms rather than evaluating depression itself. ${ }^{11,39,40}$ This could be the basis for the differences in data obtained between our study and other studies.

An insufficient number of studies have evaluated the relationships between anxiety disorders and SD in patients with FM. Anxiety disorders are more prevalent and difficult to evaluate than depression in community-based study and may be less interesting to study. ${ }^{24,41}$ Although, the prevalence of anxiety disorders in FM was higher than other chronic pain conditions, ${ }^{42}$ this is the first study to evaluate SD and anxiety disorders separately using the SCID-I in patients with FM. Patients with FM and any SD were more likely to 
exhibit an anxiety disorder or anxiety disorder not otherwise specified, as compared to those in the control group in our study. No differences were observed in the presence of any $\mathrm{SD}$ and $\mathrm{OCD}, \mathrm{GAD}$, bipolar disorder, specific phobia, panic disorder, or posttraumatic stress disorder between the two groups. However, patients with FM and sexual aversion disorder had a significantly higher incidence of OCD, whereas patients with FM and dyspareunia had a significantly higher incidence of GAD. Aydin et $\mathrm{al}^{11}$ reported a negative correlation between State-Trait Anxiety Inventory and Female Sexual Function Index scores. Our findings are generally consistent with published findings.

This is the first study to evaluate the relationship between SD and personality disorders in patients with FM using the Structured Clinical Interview for DSM, Revised Third Edition Personality Disorders. We found no differences in SD between patients with FM with and without a personality disorder. However, a significant relationship was revealed between sexual aversion and avoidance disorders and dependent personality disorder. No study has examined the relationships between personality disorders and SD in patients with FM.

In our study, $46.9 \%$ of patients with FM had a mood or anxiety disorder, as compared to $5.3 \%$ in the control group. The prevalence of any psychiatric disorder in patients with FM was significantly higher than that in the control group used in this study and in the general population. ${ }^{41,43}$ Our findings are consistent with the $48 \%-77.3 \%$ frequency of Axis I disorders reported previously. ${ }^{24,26} \mathrm{We}$ found a mood disorder prevalence of $28.1 \%$, whereas that for any anxiety disorder was $18.8 \%$. This finding corroborates previously reported rates of $19.4 \%-34.8 \%$ for mood disorders and $11.6 \%-32.2 \%$ for anxiety disorders. ${ }^{24,26,44}$ The most common Axis I disorders were major depression (26\%) and GAD (8.3\%), which is consistent with previous studies. ${ }^{26,44}$ Major depression and GAD were observed more frequently in the patient group than those in the control group.

A limited number of studies have examined the relationships between patients with FM and personality disorders. Thieme et $\mathrm{al}^{24}$ reported an $8.7 \%$ prevalence of personality disorders using similar diagnostic methods. We determined a prevalence of $13.5 \%$ in the current study. Uguz et al ${ }^{30}$ reported a $31.1 \%$ prevalence of personality disorders, whereas Rose et $\mathrm{a}^{45}$ reported a rate of $47.6 \%$. These two figures are considerably higher than the data we obtained. Another difference between other studies and ours is the lack of a significant difference in personality disorders when comparing patients with FM and controls. In our study, only histrionic personality disorder (10.4\%) was significantly more frequent in the FM patient group than that in the control group. Previous studies have found that OCD, passive-aggressive personality disorder, and avoidant personality disorder are significantly more frequent in the patient groups than in the control groups; however, no such difference was observed in our study. A higher diagnostic rate of personality disorders in previous studies may be related to clinicians diagnosing personality disorders who were not blinded to the fact that the patients also had FM. In the current study, the psychiatrists were blinded as to whether patients had FM and, therefore, may have shown less bias toward a personality disorder diagnosis.

Some limitations of our study should be mentioned. The first limitation is the relatively low number of participants. Second, no scale was used to assess FM severity. A third limiting factor was that the study was conducted in a university hospital setting. We did not consider the marital satisfaction, which might be one of the conditions that may affect the sexual function. This is another limitation of the study.

\section{Conclusion}

SD and mood and anxiety disorders are commonly seen in patients with FM. After excluding organic causes of SD, pain rather than a mood disorder played a greater role in the etiology of SD in patients with FM. Large-scale studies with the patient and the control groups examining SD and related factors are needed.

\section{Disclosure}

The authors report no conflicts of interest in this work.

\section{References}

1. Laumann EO, Nicolosi A, Glasser DB, et al. Sexual problems among women and men aged 40-80 y: prevalence and correlates identified in the Global Study of Sexual Attitudes and Behaviors. Int J Impot Res. 2005;17(1):39-57.

2. Laumann EO, Paik A, Rosen RC. Sexual dysfunction in the United States: prevalence and predictors. JAMA. 1999;281(6):537-544.

3. Mercer CH, Fenton KA, Johnson AM, et al. Sexual function problems and help seeking behaviour in Britain: national probability sample survey. BMJ. 2003;327(7412):426-427.

4. Rosen RC, Laumann EO. The prevalence of sexual problems in women: how valid are comparisons across studies? Commentary on Bancroft, Loftus, and Long's (2003) "distress about sex: a national survey of women in heterosexual relationships". Arch Sex Behav. 2003;32(3):209-211; discussion 213-206.

5. İncesu C. Cinsel işlevler ve cinsel işlev bozuklukları [Sexual function and sexual dysfunction]. Klinik Psikiyatri. 2004;3:3-13. Turkish.

6. Tarcan T, Park K, Goldstein I, et al. Histomorphometric analysis of agerelated structural changes in human clitoral cavernosal tissue. $J$ Urol. 1999;161(3):940-944.

7. Rico-Villademoros F, Calandre EP, Rodriguez-Lopez CM, et al. Sexual functioning in women and men with fibromyalgia. J Sex Med. 2012;9(2):542-549.

8. Tristano AG. The impact of rheumatic diseases on sexual function. Rheumatol Int. 2009;29(8):853-860.

9. Shaver JL, Wilbur J, Robinson FP, Wang E, Buntin MS. Women's health issues with fibromyalgia syndrome. $J$ Women's Health. 2006;15(9): 1035-1045. 
10. Orellana C, Casado E, Masip M, Galisteo C, Gratacos J, Larrosa M. Sexual dysfunction in fibromyalgia patients. Clin Exp Rheumatol. 2008; 26(4):663-666.

11. Aydin G, Basar MM, Keles I, Ergun G, Orkun S, Batislam E. Relationship between sexual dysfunction and psychiatric status in premenopausal women with fibromyalgia. Urology. 2006;67(1):156-161.

12. Tikiz C, Muezzinoglu T, Pirildar T, Taskn EO, Frat A, Tuzun C. Sexual dysfunction in female subjects with fibromyalgia. J Urol. 2005;174(2):620-623.

13. Unlu E, Ulas UH, Gurcay E, et al. Genital sympathetic skin responses in fibromyalgia syndrome. Rheumatol Int. 2006;26(11):1025-1030.

14. Ostensen M. New insights into sexual functioning and fertility in rheumatic diseases. Best Pract Res Clin Rheumatol. 2004;18(2):219-232.

15. Wolfe F, Anderson J, Harkness D, et al. Work and disability status of persons with fibromyalgia. $J$ Rheumatol. 1997;24(6):1171-1178.

16. Wolfe F, Smythe HA, Yunus MB, et al. The American college of rheumatology 1990 criteria for the classification of fibromyalgia. Report of the multicenter criteria committee. Arthritis Rheum. 1990;33(2): $160-172$

17. Ablin JN, Gurevitz I, Cohen H, Buskila D. Sexual dysfunction is correlated with tenderness in female fibromyalgia patients. Clin Exp Rheumatol. 2011;29(6 suppl 69):S44-S48.

18. Lawrence RC, Felson DT, Helmick CG, et al; National Arthritis Data Workgroup. Estimates of the prevalence of arthritis and other rheumatic conditions in the United States. Part II. Arthritis Rheum. 2008; 58(1):26-35.

19. Shuster J, McCormack J, Pillai Riddell R, Toplak ME. Understanding the psychosocial profile of women with fibromyalgia syndrome. Pain Res Manag. 2009;14(3):239-245.

20. White KP, Speechley M, Harth M, Ostbye T. The London Fibromyalgia Epidemiology Study: comparing the demographic and clinical characteristics in 100 random community cases of fibromyalgia versus controls. J Rheumatol. 1999;26(7):1577-1585.

21. Amital D, Fostick L, Polliack ML, et al. Posttraumatic stress disorder, tenderness, and fibromyalgia syndrome: are they different entities? J Psychosom Res. 2006;61(5):663-669.

22. ArnoldR, Ranchor AV, Sanderman R, Kempen GI, Ormel J, SuurmeijerTP The relative contribution of domains of quality of life to overall quality of life for different chronic diseases. Qual Life Res. 2004;13(5): 883-896.

23. Raphael KG, Janal MN, Nayak S. Comorbidity of fibromyalgia and posttraumatic stress disorder symptoms in a community sample of women. Pain Med. 2004;5(1):33-41.

24. Thieme K, Turk DC, Flor H. Comorbid depression and anxiety in fibromyalgia syndrome: relationship to somatic and psychosocial variables. Psychosom Med. 2004;66(6):837-844.

25. Malt EA, Berle JE, Olafsson S, Lund A, Ursin H. Fibromyalgia is associated with panic disorder and functional dyspepsia with mood disorders. A study of women with random sample population controls. J Psychosom Res. 2000;49(5):285-289.

26. Epstein SA, Kay G, Clauw D, et al. Psychiatric disorders in patients with fibromyalgia. A multicenter investigation. Psychosomatics. 1999;40(1):57-63.

27. Wolfe F, Ross K, Anderson J, Russell IJ, Hebert L. The prevalence and characteristics of fibromyalgia in the general population. Arthritis Rheum. 1995;38(1):19-28.
28. Hudson JI, Goldenberg DL, Pope HG Jr, Keck PE Jr, Schlesinger L. Comorbidity of fibromyalgia with medical and psychiatric disorders. Am J Med. 1992;92(4):363-367.

29. Goldenberg DL. Fibromyalgia syndrome a decade later: what have we learned? Arch Intern Med. 1999;159(8):777-785.

30. Uguz F, Cicek E, Salli A, et al. Axis I and Axis II psychiatric disorders in patients with fibromyalgia. Gen Hosp Psychiatry. 2010;32(1): 105-107.

31. Wewers ME, Lowe NK. A critical review of visual analogue scales in the measurement of clinical phenomena. Res Nurs Health. 1990;13(4): $227-236$.

32. First MB, Spitzer RL, Gibbon M, Williams JBW. Structured Clinical Interview for DSM-IV Clinical Version (SCID-I/CV). Washington, DC: American Psychiatric Press; 1997.

33. Spitzer RL, Williams JBW, Gibbon M, First M. Manual for the Structured Clinical Interview for DSM-III-R Personality Disorders. Washington, DC: American Psychiatric Press; 1990.

34. Akdemir A, Turkcapar MH, Orsel SD, Demirergi N, Dag I, Ozbay MH. Reliability and validity of the Turkish version of the Hamilton Depression Rating Scale. Compr Psychiatry. 2001;42(2):161-165.

35. Yazıcı MK, Demir B, Tanrıverdi N, Karaağaoğlu E, Yolaç P. Hamilton Anksiyete Değerlendirme Ölçeği, değerlendiriciler arası güvenilirlilik ve geçerlilik çalışması [Hamilton Anxiety Rating Scale: interrater reliability and validity study]. Turk Psikiyatri Derg. 1998;9:1147. Turkish.

36. da Costa ED, Kneubil MC, Leão WC, Thé KB. Assessment of sexual satisfaction in fibromyalgia patients. Einstein. 2004;2(3):177-181.

37. Ryan S, Hill J, Thwaites C, Dawes P. Assessing the effect of fibromyalgia on patients' sexual activity. Nurs Stand. 2008;23(2):35-41.

38. Prins MA, Woertman L, Kool MB, Geenen R. Sexual functioning of women with fibromyalgia. Clin Exp Rheumatol. 2006;24(5): $555-561$.

39. Kool MB, Woertman L, Prins MA, Van Middendorp H, Geenen R. Low relationship satisfaction and high partner involvement predict sexual problems of women with fibromyalgia. J Sex Marital Ther. 2006; 32(5):409-423.

40. Yilmaz H, Yilmaz SD, Polat HA, Salli A, Erkin G, Ugurlu H. The effects of fibromyalgia syndrome on female sexuality: a controlled study. J Sex Med. 2012;9(3):779-785.

41. Vicente B, Kohn R, Rioseco P, Saldivia S, Baker C, Torres S. Population prevalence of psychiatric disorders in Chile: 6-month and 1-month rates. Br J Psychiatry. 2004;184:299-305.

42. McBeth J, Silman AJ. The role of psychiatric disorders in fibromyalgia. Curr Rheumatol Rep. 2001;3(2):157-164.

43. Bijl RV, Ravelli A, van Zessen G. Prevalence of psychiatric disorder in the general population: results of The Netherlands Mental Health Survey and Incidence Study (NEMESIS). Soc Psychiatry Psychiatr Epidemiol. 1998;33(12):587-595.

44. Raphael KG, Janal MN, Nayak S, Schwartz JE, Gallagher RM. Psychiatric comorbidities in a community sample of women with fibromyalgia. Pain. 2006;124(1-2):117-125.

45. Rose S, Cottencin O, Chouraki V, et al. Importance des troubles de la personnalité et des comorbidités psychiatriques chez 30 patients atteints de fibromyalgie [Study on personality and psychiatric disorder in fibromyalgia]. Presse Med. 2009;38(5):695-700. French.
Neuropsychiatric Disease and Treatment

\section{Publish your work in this journal}

Neuropsychiatric Disease and Treatment is an international, peerreviewed journal of clinical therapeutics and pharmacology focusing on concise rapid reporting of clinical or pre-clinical studies on a range of neuropsychiatric and neurological disorders. This journa is indexed on PubMed Central, the 'PsycINFO' database and CAS,

\section{Dovepress}

and is the official journal of The International Neuropsychiatric Association (INA). The manuscript management system is completely online and includes a very quick and fair peer-review system, which is all easy to use. Visit http://www.dovepress.com/testimonials.php to read real quotes from published authors. 